\title{
Como SE ESCREVE “LibERDADE"? NARRATIVAS SOBRE A REVOLUÇÃo de 25 dE ABRIL DE 1974 NA IMPRENSA BRASILEIRA
}

\author{
Camila Garcia Kieling
}

\begin{abstract}
Resumo
Este artigo propõe uma recomposição da intriga de narrativas sobre a Revolução de 25 de Abril de 1974 em Portugal a partir da cobertura de dois jornais brasileiros de referência: o paulistano O Estado de S. Paulo e o carioca Jornal do Brasil. Compreendemos a narrativa jornalística como uma ordenadora do tempo na contemporaneidade, exprimindo uma "circulação generalizada da percepção histórica" (Nora, 1979, p. 180), mobilizada pela emergência de um novo fenômeno: o acontecimento. O incomum golpe de Estado em Portugal mexeu com o imaginário político mundial, reavivando confrontos entre esquerda e direita. Nesse momento, no Brasil, a ditadura militar completava 10 anos e iniciava-se o mandato do quarto presidente integrante das Forças Armadas. As narrativas são analisadas sob diferentes pontos de vista: por meio da organização dos fatos no tempo, da construção das personagens, das projeções para o futuro ou, ainda, da ressignificação do passado.
\end{abstract}

\section{How DO YOU SPELL “FREEDOM"? NARRATIVES ABOUT THE 25 April 1974 Revolution IN THE BrAZILIAN PRESS}

\begin{abstract}
This paper proposes a recomposition of the intrigue of journalistic narratives on the Revolution of April 25, 1974 in Portugal based on the coverage of two Brazilian newspapers: O Estado de S. Paulo and Jornal do Brasil. The journalistic narrative is understood as a time orderer in the contemporaneity, expressing a "generalized circulation of historical perception" (Nora, 1979, p. 180), mobilized by the emergence of a new phenomenon: the event. The unusual coup d'état in Portugal stirred the world's political imagination, reviving confrontations between left and right. At that moment, in Brazil, the military dictatorship completed 10 years and the fourth president of the Armed Forces was beginning its mandate. Narratives are analyzed from different points of view: the organization of facts in time, the construction of characters, projections for the future, or the re-signification of the past.
\end{abstract}




\section{INTROdUÇÃo: A REVOLUÇÃo dos Cravos E O CONTEXTO BRASILEIRO}

A Revolução de 25 de Abril de 1974 e o Processo Revolucionário em Curso (PREC) ao qual ela deu início mexeram com o ânimo da imprensa de todo o mundo: "Portugal era olhado como o palco de um confronto definidor entre esquerda e direita e terá sido essa uma das razões pelas quais a sua agitação tanto apaixonou a opinião pública mundial" (Vieira \& Monico, 2014, p. 337). O incomum golpe de Estado perpetrado por militares que, entre idas e vindas, levou efetivamente a um processo democrático foi acompanhado pelo mundo com olhos incrédulos e esperançosos.

Antes da Revolução, Portugal vivia sob um regime fechado' que ficou conhecido como Estado Novo ou Salazarismo (1933-1974), denominação que faz referência ao seu principal líder, António de Oliveira Salazar (1889-1970). O Estado Novo português foi muito mais que um Estado forte e repressivo. $O$ regime foi também sustentado por um imaginário poderoso, espalhado por todas as áreas da vida dos portugueses, da política e economia à educação e divertimentos. Martins (1992, p. 194), ao estudar os manuais escolares durante o período, compreende esses textos como "um sistema cultural, um sistema de símbolos em interação, o que quer dizer, como uma rede ou uma teia de significações que se entrecruzam" que integram um "corpo simbólico, que ao mesmo tempo age sobre a vida real e a reflete". $O$ autor expõe o imaginário salazarista em seu simbolismo - a saudade e o sebastianismo, o passado e o futuro - que projeta a imagem de um país antigo, tradicional e humilde, mas com aspirações de grande Império: "por um lado, pois, o desejado medievalismo, bucólico e cordato, figurado pelo tema 'boa dona de casa'. Por outro, a ambição do Império, ousada e épica, figurada pelas caravelas" (Martins, 1992, p. 198).

O 25 de Abril, Revolução que deu fim à ditadura, foi conduzido pelo Movimento das Forças Armadas (MFA) e iniciou o processo que levou à implantação de um regime democrático, com a aprovação da Constituição de 25 de abril de 1976.

Em 1974, no Brasil, a ditadura iniciada com o golpe contra o presidente João Goulart completava 10 anos e encaminhava-se a posse do quarto presidente militar. A oposição festejou o sucesso da insurreição portuguesa. Curiosamente, o governo brasileiro, que cultivava relações amistosas com governos ditatoriais de direita - como os de Pinochet no Chile e de Stroessner no Paraguai - logo reconheceu a Junta de Salvação Nacional (JSN) que se instalou no governo português e, ao mesmo tempo, ofereceu asilo político ao presidente da República deposto, Américo Tomás, e ao presidente do Conselho de Ministros, sucessor de Salazar, Marcelo Caetano. O inusitado posicionamento esteve relacionado com a questão colonial, especialmente com as guerras de independência de Angola, Moçambique e Guiné, já que o Brasil tinha interesse em herdar de Portugal a influência cultural e comercial sobre as colônias (Martinho, 2007).

\footnotetext{
' Foram 48 anos de ditadura, de 1926 a 1974. Nesse percurso estão a Ditadura Militar (1926 a 1933), o Estado Novo Salazarista (1933 a 1968) e o Estado Novo Marcelista (de 1968 a 1974, período no qual Marcelo Caetano assume a presidência do Conselho de Ministros após o afastamento, por motivos de saúde, de António Salazar) (Rosas, 2013). Sobre a natureza nacionalista e clerical do Estado Novo, a sua forma autoritária e antidemocrática e a sua legitimidade corporativa, ver Martins (2017). E sobre o imaginário salazarista, ver, também, Martins (2014).
} 
A mobilização da opinião pública sobre este evento de ruptura institucional, acompanhado por jornais, revistas, rádio e televisão (esta última teve um papel inédito nas revoluções do século XX até aquele momento) - está relacionado com o que Nora (1979; 1983), ao discutir a questão da especificidade da chamada história contemporânea, vê como um vasto fenômeno de democratização da história, derivado de tudo o que se costuma entender por "mundialização" - as guerras mundiais, a rapidez das comunicações, a penetração das economias em escala global. Trata-se de uma "circulação generalizada da percepção histórica" que culmina em um fenômeno novo: o acontecimento" (Nora, 1979, p. 180). De acordo com o autor, a comunicação de massas desempenha um papel central nesse processo: "os mass media têm agora um monopólio sobre a história. Nas sociedades contemporâneas, é através da mídia e somente através dela que um acontecimento nos atinge e não nos pode escapar" (Nora, 1983, p. 5). Mais do que simplesmente meios de transmissão de mensagens, os mass media abarcam a própria condição da existência dos acontecimentos.

Mediada e irremediavelmente coberta pela película da atualidade, a percepção da mudança é impactada por essa nova forma de conhecimento do mundo: o acontecimento. Nesse sentido, os processos de mudanças econômicas, políticas, culturais vêm sendo, ao longo dos séculos XX e XXI, reconfigurados pela ação dos meios de comunicação de massa, em um processo que pode ser explicado, ao menos em parte, pela mitologia da prática jornalística. O jornalismo funda-se em um paradoxo, uma vez que não deixa de lançar mão de recursos mitológicos, como o da "construção de uma narrativa sobre si mesma como entidade mítica que administra a verdade dos fatos sociais, e mais, a retórica encantatória na narração fragmentária sobre a atualidade" (Sodré, 2009, p. 12). A mitologia do liberalismo encobre as disputas em torno da atribuição de sentidos que permeiam a constituição do discurso jornalístico ao mesmo tempo em que confere à notícia o estatuto de esclarecimento neutro.

É sobretudo a partir do século XX, através da ação dos meios de comunicação de massa, que a mudança - ou leitura midiática dessa noção - emerge como um valor preponderante na consciência histórica ocidental. Nora (1979, p. 184) também assinala a dimensão imaginária que a mediação de massas provoca no acontecimento: "na medida em que efetivamente o acontecimento se tornou intimamente ligado à sua expressão, sua significação intelectual, próxima de uma primeira forma de elaboração histórica, esvaziou-se a favor de suas virtualidades emocionais. A realidade propõe, o imaginário dispõe". De "espelho do real", o jornalismo é encarado como uma narrativa e como uma tecnologia do imaginário (Silva, 2006). Esta atividade provoca um conhecimento do mundo através de suas técnicas, interpelando os fatos por meio de sua espetacularização, configurando, assim, uma tecnologia do imaginário: "os fatos só existem como narrativas, entre as quais a jornalística” (Silva, 2006, p. 107).

Em termos teórico-metodológicos, consideramos a narrativa jornalística como narrativa do cotidiano, mediadora das ações no tempo, organizadora da experiência entre o passado, o presente e o futuro: "o jornalismo observa o mundo desde o atual, ancora seu relato no presente para relatar o passado e antecipar o futuro. Opera uma mediação 
que é, ao mesmo tempo, linguística e temporal" (Motta, 2005, p. 9). Nesse sentido, o texto é ponto de partida, mas não perdemos de vista o fato de que ele só produz sentidos na relação com atores históricos humanos e com o contexto.

Para tratar das narrativas jornalísticas sobre a Revolução de 25 de Abril de 1974, interessou-nos, sobretudo, exemplares da imprensa brasileira de referência, com circulação nacional e tiragem expressiva. Buscamos, ainda, a composição de um corpus formado por jornais que representassem grupos ideológicos e linguagens jornalísticas diferenciadas. A seleção compreende, assim, O Estado de S. Paulo, matutino ligado aos cafeicultores paulistas e de trajetória liberal, conservadora e anti-trabalhista, e Jornal do Brasil, diário carioca marcado pelo diálogo com as classes populares, pioneiro na modernização da linguagem gráfica e editorial no jornalismo brasileiro nos anos 1960. Ambos foram favoráveis ao golpe civil-militar que em abril de 1964 destituiu o presidente João Goulart. Dez anos mais tarde, a relação com os militares apresentava algum desgaste, perceptível nas nuances e ambiguidades da cobertura da revolução portuguesa.

Os acontecimentos de 25 de abril de 1974 foram acompanhados, ao mesmo tempo, com esperança, ceticismo e incredulidade, no mundo todo. Àquela altura, poderia parecer mais um golpe militar que encobria intenções despóticas com promessas de libertação, mas também um revigorante sopro de liberdade e um sério aviso a outras ditaduras, seja na Europa ou na América do Sul - em países como Espanha, Grécia, Chile e Brasil. Vemos, assim, que o 25 de Abril traz à tona uma série de disputas de poder e expõe a complexidade das relações políticas naquele momento histórico, relatadas e interpretadas pela imprensa da época.

\section{Portugal e o Futuro, o Levante das Caldas e a derrocada do regime}

A Revolução de 25 de abril de 1974 e o Processo Revolucionário em Curso (PREC) ao qual ela deu início mexeram com o ânimo da imprensa mundial: "Portugal era olhado como o palco de um confronto definidor entre esquerda e direita e terá sido essa uma das razões pelas quais a sua agitação tanto apaixonou a opinião pública mundial" (Vieira \& Monico, 2014, p. 337). O incomum golpe de Estado perpetrado por militares que, entre idas e vindas, levou efetivamente a um processo democrático foi acompanhado por olhos incrédulos e esperançosos.

A essa altura, a imprensa brasileira estava sob censura. De acordo com Fico (2012, p. 87), a prática existiu desde o começo do regime militar, mas acentuou-se após dezembro de 1968, com a edição do Ato Institucional número cinco. A partir daí, a censura "sistematizou-se, tornou-se rotineira e passou a obedecer instruções especificamente emanadas dos altos escalões do poder". A forma mais grave era a censura prévia, mas a mais comum eram as proibições determinadas, transmitidas às redações através de bilhetinhos ou por telefone (Fico, 2012).

Matutino e diário, $O$ Estado de S. Paulo contribuiu ativamente para a efetivação do golpe civil-militar de 1964 no Brasil. Depois do golpe, a relação entre o jornal e os militares torna-se cada vez mais tensa, e atinge o auge em dezembro de 1968, após a 
edição do Ato Institucional número cinco, com a publicação do editorial "Instituições em frangalhos". A edição do jornal foi apreendida e instituiu-se a censura prévia sobre a redação, que seria suspensa apenas em janeiro de 1975.

No Brasil, Ernesto Geisel toma posse em 15 de março de 1974, ocasião em que, de acordo com O Estado de S. Paulo, "faz apelo pela unidade" (Geisel faz apelo pela unidade, 1974, p. 1), indicando que o apelo à coesão das Forças Armadas continua impregnado no imaginário nacional. Na edição deste mesmo dia, o jornal repercute o que chama de recrudescimento da "crise político-militar em Portugal" (Recrudesce em Portugal a crise político-militar, 1974, p. 1), reportando o cercamento da Academia Militar pela Guarda Republicana por conta de uma reunião de oficiais que lá se encontravam para "debater problemas militares nacionais", voltando a vigorar o estado de alerta nos quartéis. A matéria repercute a tensão entre as Forças Armadas portuguesas e cita a questão da demissão de Spínola e Costa Gomes ocorrida na quarta-feira, 14 de março de 1974, provocada pela discordância entre os militares e o governo na condução da guerra na África.

Na página dois, a coluna do correspondente Santana Mota, contraria a matéria de capa, afirmando que "em Portugal, a situação agora é menos confusa". De acordo com o colunista, oficiais de altas patentes manifestaram apoio ao governo em sua política ultramarina. O texto se dedica, ainda, a analisar em pormenor a conduta de Spínola e a repercussão da publicação do livro Portugal e o Futuro, que veio a público em fevereiro de 1974 e provocou grande interesse, especialmente no exterior, por indicar que a solução para a guerra em territórios africanos não seria militar, mas política. Mota informa que Spínola é considerado um militar leal e disciplinado e que a publicação do livro só se deu com a anuência de seus superiores e do governo. O episódio de sua demissão também é minimizado e interpretado

como o processo mais sensato de acabar com as especulações e as tentativas de aliciamento que certamente não deixariam de ser feitas sobre o general por todos os insatisfeitos civis e militares, enquanto ele permanecesse no exercício de um cargo de tanta projeção. (Mota, 1974, p. 2)

Ao lado da matéria do correspondente está uma charge de Bigatti: em um requintado gabinete, figura um retrato de Marcelo Caetano e, dentro do cesto de lixo, está um exemplar do livro Portugal e o Futuro (Figura 1). Complementada pela leitura do texto, a charge parece remeter ao triunfo do governo frente às críticas de Spínola. Ou, em uma interpretação mais livre, pode indicar que Portugal e o futuro, sob o regime de Caetano, restam na lata do lixo. 


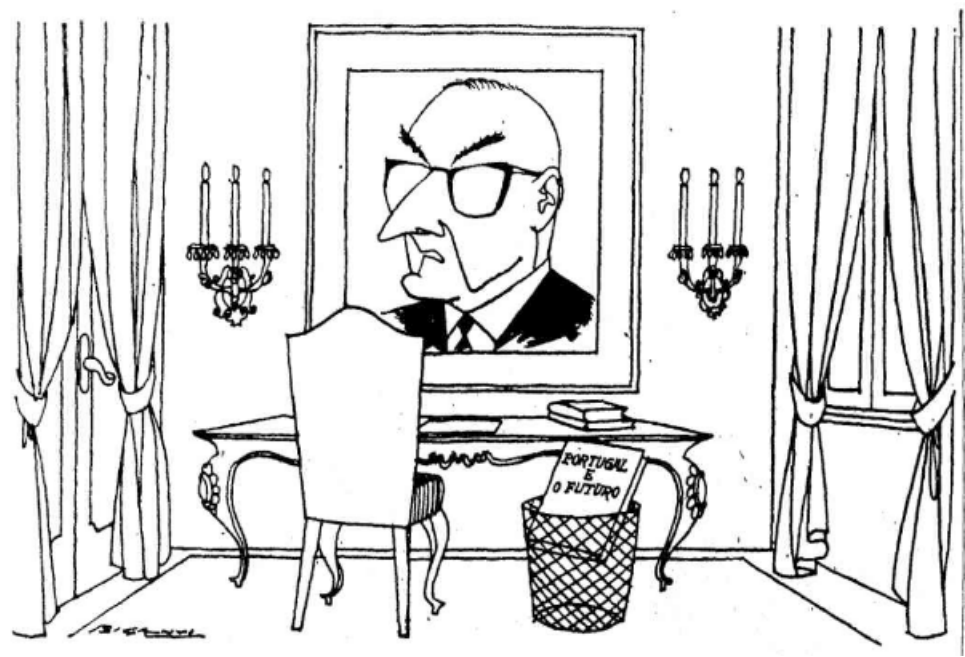

Figura 1: Portugal e o futuro na lata do lixo

Fonte: O Estado de S. Paulo, 16 de março de 1974, p. 2

Portugal e o Futuro foi publicado no Brasil pela editora Nova Fronteira, de propriedade de Carlos Lacerda, que assinou também o prefácio da edição. Nas páginas de $O$ Estado de S. Paulo aparece um reclame da obra (Figura 2), que anuncia: "o livro que abalou uma nação". O Jornal do Brasil de 27 de abril noticia que o livro se esgotou em Niterói e no Recife e que em poucos dias vendeu mais de 50 mil exemplares em São Paulo (Livro se esgota em duas cidades, 1974, p. 9). Lacerda - que foi articulador do golpe de 1964 no Brasil e feroz opositor do presidente deposto João Goulart, vivia agora em atrito com os militares e teve seus direitos políticos suspensos por 10 anos em 1968 - dedica-se então ao jornalismo e a atividades empresariais. Colaborador de $O$ Estado de S. Paulo, assina um texto na edição de 9 de abril intitulado "Portugal acha a solução". Nele, Lacerda classifica de "irrefutável" a análise e a proposta de solução de Spínola para a situação portuguesa, na qual enfatiza a dimensão da democratização de Portugal para a solução do problema colonial. Lacerda afirma, ainda, que "há um movimento em marcha em Portugal" e que a mudança acontecerá inevitavelmente. Invoca a experiência própria para advertir: "na medida em que posso alegar uma experiência na matéria, digo que o atraso de uma solução tornará inevitável a ascensão direta das Forças Armadas ao poder" (Lacerda, 1974, p. 5).

Em 17 de março, a manchete principal de capa de O Estado de S. Paulo confirma a persistência da crise em Portugal. A marcha do $\mathrm{V}$ Regimento de Infantaria de Caldas da Rainha foi contida, mas o clima de tensão crescente é caracterizado por $O$ Estado de S. Paulo através de vários aspectos: a prisão de mais de 100 oficiais, restabelecimento da prontidão rigorosa em todo o país, distribuição de panfletos nas ruas de Lisboa criticando o tratamento dispensado pelo governo aos territórios africanos e defendendo a solução política das questões do ultramar, o bloqueio das entradas e saídas de Lisboa, o reforço da guarda do presidente Américo Tomás e do primeiro-ministro Marcelo Caetano. A matéria atribui a crise à publicação do livro de Spínola: "o paradeiro do General Spínola - autor do livro Portugal e o Futuro, cuja publicação levou à atual crise 
político-militar - é desconhecido e ignorado até mesmo por sua mulher". São publicados trechos da nota oficial do governo português descrevendo os fatos e afirmando que "a ordem e a calma reinam em todo o país". Parte das fontes das informações não é explicitada, citando "rumores" e "observadores" para descrever um momento grave: "segundo observadores, trata-se da mais grave crise que se registra nos últimos 40 anos em Portugal". Para O Estado de S. Paulo, ainda, Caetano encontra-se pressionado, por um lado, pelos partidários da tese de Spínola e, por outro, pelos apoiadores da "linha dura" de Américo Tomás, "favoráveis à preservação dos territórios africanos por todos os meios" (Lisboa sufoca revolta mas crise se agrava, 1974, p. 1), enquanto abre-se a possibilidade de espaço na Comunidade Europeia.

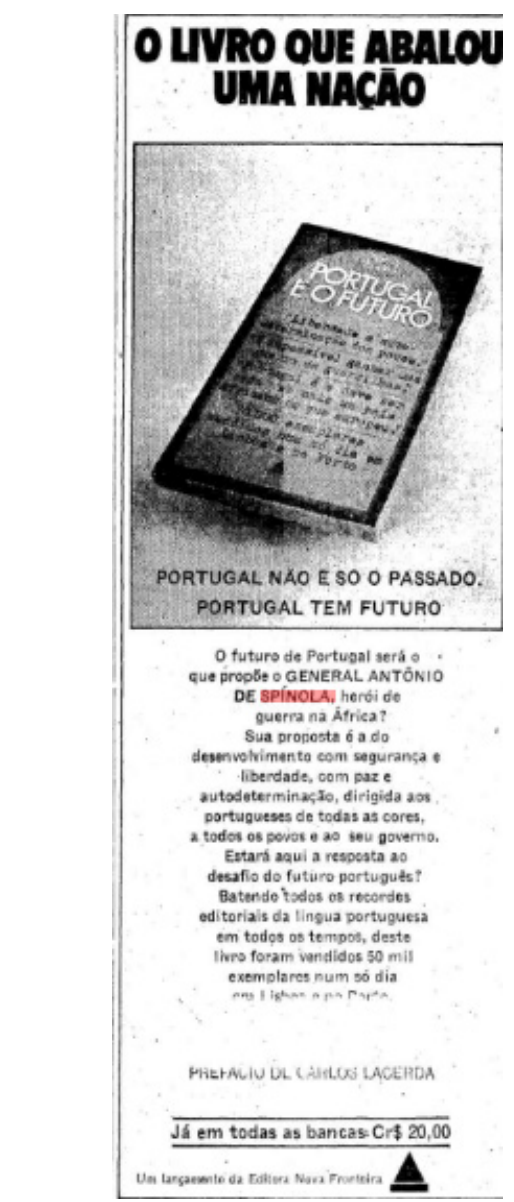

Figura 2: Anúncio do livro Portugal e o Futuro

Fonte: O Estado de S. Paulo, 7 de abril de 1974, p. 2

O governo português procura demonstrar certo controle da situação e isso se reflete, inclusive, nas relações com o Brasil. Ainda na capa de 17 de março, ao lado da matéria principal, está uma matéria secundária que informa que o chanceler português Rui Patrício "refutou energicamente a denominação de Comunidade Afro-Luso-Brasileira" a um "sistema de relações econômicas entre Brasília, Lisboa e colônias na África. Para Patrício, a expressão deve limitar-se a Comunidade Luso-Brasileira" (Patrício rejeita 
alteração, 1974, p. 1). O chanceler, à altura do levante das Caldas, encontrava-se em Brasília, onde concedeu entrevista à imprensa.

Mesmo assim, a tensão aumenta, Spínola desponta como liderança, e o controle da revolta de Caldas da Rainha não é considerado uma vitória definitiva. O Estado de $S$. Paulo dedica-se a traçar um perfil de Spínola (Os feitos de Spínola o destacam como líder, 1974, p. 14), no qual é caracterizado como um militar e administrador público de alta capacidade, demonstrada especialmente no período em que foi governador e comandante da Guiné, gozando de respeito e estima entre os soldados.

A 28 de março O Estado de S. Paulo publica notícia que afirma que "A sublevação em Portugal fazia parte de conspiração". Dá espaço, ainda, à resposta, por parte da Frente de Libertação de Moçambique (Frelimo), à solução spinolista para as colônias portuguesas na África. A Frelimo rejeitava a proposta e afirmava considerar Spínola "um filósofo fascista" (Frelimo rejeita a proposta, 1974, p. 2).

\section{A explosão do 25 de Abril}

Nos jornais brasileiros analisados, a primeira referência ao movimento militar da revolução em Portugal aparece no Jornal do Brasil de 25 de abril de 1974. Em notícia na página 14, indicando o segundo clichê da página naquela edição, o jornal informa que "tropa rebelada marcha em direção à [sic] Lisboa":

tropas do $5^{\circ}$ Regimento de Caçadores ocuparam, na madrugada de hoje, a Rádio Clube de Portugal, que passou a transmitir comunicados em que os militares pedem 'a todas as forças do Exército e da polícia a máxima cautela para evitar qualquer choque'. (Tropa rebelada marcha em direção à Lisboa, 1974, p. 14)

O jornal transcreve na íntegra o primeiro comunicado do que chama de "um" Movimento das Forças Armadas, que assinava um documento que circulava clandestinamente "no qual se pedia uma reavaliação das políticas seguidas por Portugal em suas guerras na África". No terceiro clichê da edição de 25 de abril, foi possível publicar mais detalhes. O título torna-se "Rebeldes tentam evitar choque armado em Lisboa". Refere-se a um "levante militar", de acordo com a ANI (Agência Noticiosa de Informação), de proporção e natureza ainda desconhecidas. Ressaltamos que o Jornal do Brasil procura a agência oficial do governo português (mas cita, ainda, AGP e UPI como fontes) para confirmar a existência do movimento cujas intenções ainda não estão claras, já que em suas transmissões "o Movimento das Forças Armadas não esclarece o que pretende, quem lidera, se é legalista ou parte do movimento contra o governo" (Rebeldes tentam evitar choque armado em Lisboa, 1974, p. 14).

A 26 de abril de 1974, toda a capa de O Estado de S. Paulo é dedicada a Portugal. O diário paulistano opta pela manchete: "Golpe militar derruba o governo português". No lead, vemos que o Estado centra os acontecimentos nos oficiais de mais alto escalão. Além das lideranças militares, $O$ Estado de S. Paulo ressalta as promessas de restauração 
da democracia, de convocação de uma Assembleia Constituinte e de eleições gerais e livres. A dimensão popular aparece na capa, destacada em texto secundário intitulado "O novo regime é aclamado nas ruas de Lisboa". São relatos de detalhes do cotidiano, do clima festivo das ruas que demonstram o entusiasmo popular com os acontecimentos.

Outros dois títulos utilizam como recurso o uso de sinais de precisão e exatidão (neste caso, o horário) como síntese dos textos: "Apenas 12 horas" e "Às 4 da tarde, o final de uma era". O primeiro refere-se ao tempo decorrido entre as primeiras movimentações de tanques em Santarém, às quatro horas da manhã, e a entrada de Spínola no Quartel do Carmo, às $18 \mathrm{~h}$, sintetizando e precisando uma cronologia dos fatos. Em "Às 4 da tarde, o final de uma era", o correspondente Santana Mota destaca o protagonismo da jovem oficialidade:

aparentemente, toda a oficialidade que participou do golpe é constituída de jovens, a maioria com patentes inferiores à de major. Em declarações pelo rádio, esses oficiais disseram que pretendem não apenas abolir o regime, mas também realizar imediatamente eleições livres, com plena liberdade de expressão e reunião. (Mota, 1974, p. 1)

Os dois últimos textos da capa, localizados ao pé da página, tratam de projeções e desdobramentos dos acontecimentos, selecionadas pelo veículo como relevantes. Neste caso, O Estado de S. Paulo procura analisar os reflexos do golpe em Portugal no Brasil e nas colônias portuguesas na África. "Itamaraty não foi surpreendido", texto assinado pela sucursal de Brasília, informa que o Itamaraty, desde a publicação do livro Portugal e o Futuro, entendia que mudanças na política portuguesa eram inevitáveis e, por isso, não se surpreendeu, talvez em uma tentativa de minimizar a magnitude dos acontecimentos e seus possíveis reflexos na oposição ao regime militar no Brasil. O texto traz como informação a "confidência" de um diplomata a um jornalista, afirmando que "o Brasil se encontrava numa situação delicada, pois pretendia aproximar-se dos árabes e africanos e Portugal representava um empecilho" (Itamaraty não foi surpreendido, 1974 p. 1). Àquela altura, as autoridades ainda guardavam silêncio ou eram evasivas. Dos territórios africanos, a "notícia", até então, era apenas o silêncio.

Em editorial, O Estado de S. Paulo interpreta os acontecimentos em Portugal à luz da geopolítica, da Guerra Fria e do esgotamento do salazarismo frente aos problemas do País. Compara o movimento de 25 de abril com o começo da ditadura portuguesa em 1926, afirmando que as mesmas "classes armadas (...) repetem o gesto de há quase meio século e constituem uma junta revolucionária, igualmente intitulada de salvação nacional, sobre os escombros do governo Marcelo Caetano" (A queda do regime português, 1974, p. 3). Adepto das soluções autoritárias, o diário sugere que se realize, antes das eleições, um "processo de reeducação das massas, para que aprendam a fazer uso da liberdade inebriante de pensamento, de reunião, de associação, de expressão e de voto" (A queda do regime português, 1974, p. 3).

A cobertura de $O$ Estado de S. Paulo estende-se por mais quatro páginas completas, nas quais procura contextualizar as informações ao público brasileiro, apresentando os 
protagonistas dos acontecimentos em Portugal, a questão colonial e a repercussão no Brasil e no mundo. Em relação às personagens protagonistas, O Estado de S. Paulo elege o general Spínola, o presidente Américo Tomás e o primeiro-ministro Marcelo Caetano, além do próprio Salazar. O Estado de S. Paulo procura contextualizar os fatos didaticamente, através de mapas e informações demográficas sobre as agora "províncias" na África, do perfil de personagens, de dados sobre as Forças Armadas e de textos de resgate histórico sobre o Salazarismo.

Sobre a repercussão internacional, O Estado de S. Paulo elege Londres e Paris como pontos de vista. Quase com o mesmo estatuto de Nação, está a opinião de Carlos Lacerda, indicando que essa personagem segue, apesar de agora inimigo dos militares brasileiros, no centro do palco midiático. Carlos Chagas, jornalista e ex-assessor de imprensa da presidência da República em 1969, sob o governo do general Costa e Silva, também assina a coluna. Afora as colunas assinadas e opiniões individuais, o texto noticioso afirma que o "mundo aguarda desfecho da crise" e reúne as reações, caracterizadas, em termos gerais, como de cautela e apreensão, em Londres, em Madrid e no Vaticano. Satisfação é a manifestação de diversos delegados da ONU, instituição que havia, no ano anterior, reconhecido a independência da Guiné. Na Rodésia e África do Sul, tradicionais apoiadoras da política ultramarina, "a situação portuguesa era acompanhada ontem com grande interesse" (Mundo aguarda o desfecho da crise, 1974, p. 9). Washington afirma não ter “'nenhuma informação significativa' além das notícias da imprensa" (Mundo aguarda o desfecho da crise, 1974, p. 9). A agência soviética TASS é a única a sugerir, nesse momento, uma eventual separação entre o MFA e os generais Francisco da Costa Gomes e António de Spínola, que, de acordo com essa fonte, teriam sido convidados pelos líderes da insurreição para unirem-se a eles. De outro modo, a leitura que se tem nos jornais analisados é sempre a de que esses generais já eram os líderes do movimento das Forças Armadas, e não de que se uniram no 25 de Abril.

De Paris, onde vivia exilado, aparece Mário Soares, do Partido Socialista Português. Soares demonstra total confiança no exército, diferenciando-o do exemplo das Forças Armadas do Chile que, no ano anterior, haviam deposto o socialista Salvador Allende e implantado uma ditadura liderada pelo general Augusto Pinochet: "não temos motivo para colocar em dúvida a intenção de nosso Exército de acabar com a ditadura" (Mário Soares oferece apoio, 1974, p. 9). Na mesma matéria que fala de Soares, apesar do título não indicar ("Mário Soares oferece apoio"), está a repercussão dos acontecimentos entre líderes das revoltas nos territórios africanos. De Londres, é enviada nota da Comissão para Libertação da Guiné e Moçambique. De Ottawa, Canadá, Agostinho Neto, representante do Movimento para a Libertação de Angola - MPLA, afirma que o golpe de Estado não significa a independência e que seria preciso aguardar para "verificar quais foram os verdadeiros motivos do golpe" (Mário Soares oferece apoio, 1974, p. 9).

De Londres, o correspondente Hermano Alves reporta que os "meios oficiais e oficiosos da Inglaterra" recebiam as notícias com "indisfarçável simpatia e até mesmo com entusiasmo" (Alves, 1974, p. 9). A reação da Inglaterra é de grande relevância, uma vez que a Aliança Anglo-Portuguesa é a mais antiga aliança diplomática do mundo (ainda em 
vigor) e também porque este país, que havia recentemente eleito um primeiro-ministro trabalhista, tinha grande interesse comercial nas colônias e no golpe que uma possível "composição com os nacionalistas africanos" poderia significar no apartheid da África do Sul e na supremacia branca da Rodésia. Segundo o correspondente de O Estado de S. Paulo, os jornais britânicos Guardian e The Times haviam noticiado, recentemente, a incursão de tropas da Rodésia em Moçambique.

Gilles Lapouge, correspondente na França, afirma que, apesar da falta de reações oficiais das autoridades e candidatos (a França estava em pleno período de campanha eleitoral), os acontecimentos em Portugal dominavam o noticiário em Paris. O jornalista afirma ter procurado conversar "com vários operários portugueses nas obras dos subúrbios de Paris. Poucos quiseram dar declarações. Os que falaram, disseram que não esperavam qualquer mudança importante na situação de seu país" (Lapouge, 1974, p. 9). O texto considera, ainda, a dimensão popular da revolução, até agora muito pouco explorada pela narrativa jornalística:

de qualquer maneira, a notícia foi recebida com alegria pela maior parte da população francesa. A presença de milhões de operários portugueses neste país não poderia deixar de sensibilizar a opinião pública para o problema de um povo sem direitos, perseguido por uma violenta polícia-política, levado à pobreza e ao desencanto por um regime arcaico. (Lapouge, 1974, p. 9)

Neste sentido, o artigo assinado pelo jornalista Carlos Chagas afirma que "Fim do regime apenas traduz a vontade popular" (grifo nosso):

pode-se dizer, com pouca margem de erro, que a revolução de agora teve bases estritamente populares, ainda que conduzida pelos militares portugueses. A eles coube, tão somente, acordar para a realidade e contestá-la, já que detinham os meios para tanto. Faltava uma unidade ou um denominador comum, e este surgiu com o livro do general António de Spínola, transpondo para o papel não apenas a reação de todos, mas apontando uma solução clara e precisa para o impasse. (Chagas, 1974, p. 9)

Ao mesmo tempo, o jornalista imputa os acontecimentos à falta de competência e de sensibilidade dos governantes portugueses - uma leitura que é recorrente em nossa análise - e afirma que "algumas revoluções se fazem por falta de pão, outras por falta de ordem (...) Pode-se concluir que o movimento de ontem se fez por falta de inteligência" (Chagas, 1974, p. 9).

A página 9 de $O$ Estado de S. Paulo de 26 de abril completa-se com a opinião de Carlos Lacerda. A composição da página dá à fala do ex-governador na Guanabara o estatuto de nação ou autoridade. Os demais textos demonstram uma certa cautela nessas esferas, o que se traduz em dificuldade para os jornalistas em conseguir declarações oficiais. Mesmo com os direitos políticos cassados, Lacerda não apresenta esse problema, opinando livremente, o que demonstra a relevância desta personagem na cena pública brasileira. O título é "Para Lacerda, era previsível o que aconteceu" e, na matéria, 
"De roupa esporte, muito alegre e recebendo telefonemas a todo o instante", Lacerda imputava a previsibilidade do evento à publicação do livro de Spínola (do qual, lembramos, a edição brasileira foi publicada pela editora Nova Fronteira, de propriedade do ex-governador). Com histórico de "derrubador de presidentes", a reportagem questiona se ele teria colaborado de alguma forma com a queda da ditadura portuguesa, pergunta à qual "respondeu, sério: - Infelizmente, não tive a honra de participar de nada" (Lacerda,1974, p. 9).

"Foi um grande dia para o ex-governador, que começou manifestando sua emoção e suas esperanças, que devem ser as mesmas de todos os que defendem a liberdade dos povos: - Todos estamos de parabéns, repetiu várias vezes" (Para Lacerda, era previsível o que aconteceu, 1974, p. 9). O comunismo segue sendo rechaçado no discurso de Lacerda, e é mencionado como sinônimo de anarquia. Afirma que "o que se deve fazer lá é formar uma verdadeira democracia, dissociada do comunismo" (Para Lacerda, era previsível o que aconteceu, 1974, p. 9). Assim como Chagas, Lacerda atribui à incompetência política de Marcelo Caetano o fato de o governo não ter percebido o que se passava, especialmente entre as Forças Armadas.

O Jornal do Brasil a 26 de abril opta pela manchete "Junta controla Portugal e anuncia Constituinte". A protagonista das ações, pela narrativa deste jornal, é a Junta de Salvação Nacional, que contaria com a "chancela do Movimento das Forças Armadas, denominação adotada pelos rebeldes desde o início de sua ação". O destaque são as medidas imediatas anunciadas, como a eleição de uma Assembleia Constituinte pelo voto direto. Na página dois, "Militares acabam Salazarismo e prometem eleição" informa que o anúncio oficial da Junta aconteceu imediatamente depois da rendição de Caetano, mas não esclarece qual a exata relação entre ela e o MFA. Destaca os objetivos do movimento, divulgados pelo próprio através de manifesto televisionado do General Spínola e, através da fonte "observadores diplomáticos em Lisboa", enfatiza que "os novos detentores do poder, no período de transição até a convocação de eleições gerais, se dedicarão à tarefa de eliminar da vida pública todos os elementos vinculados ao Salazarismo" (Militares acabam salazarismo e prometem eleição, 1974, p. 2), incluindo a possibilidade de um expurgo nas Forças Armadas.

Em uma cronologia da revolução ("Como foi o movimento rebelde"), Jornal do Brasil repercute a edição do jornal República, agora livre de censura e caracterizado como "liberal":

as Forças Armadas tomam o poder'. Sob uma manchete em cor vermelha, o jornal liberal República divulgou ontem um amplo relato do movimento que culminou com a queda do Primeiro-Ministro Marcelo Caetano e anunciou aos seus leitores que pela primeira vez saía às ruas sem censura. (Como foi o movimento rebelde, 1974, p. 2)

A narrativa do Jornal do Brasil dá indícios da confusão em relação às lideranças do movimento. De acordo com a cronologia apresentada, já ao final da manhã, com Lisboa tomada pelo MFA, especialmente na Praça das Carmelitas, em frente ao quartel do 
Carmo, onde Caetano estava refugiado, faltava ainda, para a imprensa, uma informação importante: "Apenas não se conheciam, ainda, os nomes dos dirigentes do movimento" (Como foi o movimento rebelde, 1974, p. 2).

A narrativa do Jornal do Brasil exalta o protagonismo de Spínola: a rendição de Caetano teria sido apressada por sua presença no local. Após a retirada do primeiro-ministro, preso, "saía o carro do General Spínola. Este, trajando seu uniforme com todas as condecorações, foi aclamado pela multidão aos gritos de "Viva Spínola. Abaixo o Fascismo. Viva Portugal" (Como foi o movimento rebelde, 1974, p. 2).

$\mathrm{Na}$ Coluna do Castello - do jornalista Carlos Castello Branco -, está a leitura de que, entre o peso da guerra e o ânimo das novas gerações está Spínola, ou seja:

a inspiração de um general dotado de visão política e coragem cívica, o qual, depois de governar a Guiné e comandar as forças repressoras, propôs em livro de larga repercussão o fim da ditadura interna em Portugal como pressuposto de sobrevivência da sua pátria e da continuidade da influência de Portugal no mundo português. (Castello Branco, 1974, p. 4)

Marcelo Caetano, a quem se refere como professor, é também considerado culpado, por Castello, pela incapacidade do governo de Portugal de superar o conservantismo da sociedade herdada de Salazar e por fazer o país seguir mergulhado no isolacionismo. Procura explorar o papel do Brasil frente a nova situação em "nossa fronteira d'além mar". Para Castello, o Brasil deve ter interesse no mundo português e não exclusivamente em Portugal, "a cuja política oferecemos o sacrifício continuado do nosso prestígio nas organizações internacionais". Vê, ainda, um papel central do Brasil na preservação de "um sistema multinacional" (Castello Branco, 1974, p. 4).

No espaço noticioso, ainda não há uma posição oficial do governo brasileiro, que aguarda uma manifestação de "um novo governo que se constitua e exerça, de fato, sua autoridade política sobre Portugal" (Brasil aguarda em silêncio, 1974, p. 4). Porém, na seção de notas curtas "Informe Jornal do Brasil" está a sentença: "Portugal - O Brasil reconhecerá o novo Governo português, imediatamente" (Informe Jornal do Brasil, 1974, p. 10). A opinião de Carlos Lacerda também tem espaço no Jornal do Brasil, na matéria "Lacerda diz que Spínola democratizará Portugal".

Em editorial, Jornal do Brasil dedica-se a analisar o papel do Brasil frente à nova configuração política portuguesa. Reforça a tese de que as mudanças nesse país eram previsíveis e que refletiam a vontade popular:

o previsível movimento militar e político que encerrou, em Portugal, o governo do Primeiro-Ministro Marcelo Caetano, foi o reconhecimento, de fato, de que a opinião pública portuguesa exigia caminhos novos para o país, que há 13 anos se exauria numa guerra inglória em suas colônias da África. O movimento foi rápido e praticamente incruento, que é a marca das ações que já surgem apoiadas no consenso popular. (Brasil-Portugal, 1974, p. 6) 
Como autoridade no espaço público, Jornal do Brasil exige atitudes dos governantes, sugerindo o imediato reconhecimento do novo governo: "o Brasil, reconhecendo imediatamente o Governo que assumiu o poder, deve pôr-se a serviço da comunidade de língua portuguesa, na antiga metrópole e nas ex-colônias". Para o jornal, Brasília já estava "suficientemente afastada" do governo português e, com as mudanças que despontam no horizonte político desse país "é imperativo não protelar esse encontro dos três mundos de cultura portuguesa: o lusitano, o africano, o brasileiro" (Brasil-Portugal, 1974 , p. 6). Em "Portugal à margem do mundo" está um resgate, assinado pelo selo "Pesquisa Jornal do Brasil", da turbulenta trajetória recente deste país em relação aos organismos internacionais, como ONU, Unesco, Organização Internacional do Trabalho e até mesmo divergências com a Igreja, amealhando diversos sinais de que se posicionava, realmente, "à margem do mundo" (Portugal à margem do mundo, 1974, p. 4).

A dimensão popular na narrativa do Jornal do Brasil está em "Povo sai às ruas da Capital em festa". São as mesmas histórias relatadas em O Estado de S. Paulo, com as mesmas citações, provavelmente pela origem em comum - a agência AFP. Também são praticamente idênticas as matérias sobre a até então possível volta de Mário Soares a Portugal.

A 27 de abril, o Jornal do Brasil destina a foto e manchete principais de capa a Portugal: "Portugal anuncia Governo civil e eleição em um ano". Os destaques, além dos indicados no próprio título e que constituem as primeiras medidas anunciadas pela Junta de Salvação Nacional, são a libertação dos presos políticos da prisão de Caxias e algumas repercussões internacionais: a intenção de pronto reconhecimento do novo governo pela Espanha, a cautela dos norte-americanos e a saudação, pela "imprensa europeia" do fim do salazarismo.

A cobertura se divide entre os acontecimentos em Lisboa e a repercussão mundial. Na primeira abordagem, está "Junta dissolve polícia e Partido salazaristas". Entre as primeiras medidas do novo governo está a destruição das instituições do passado salazarista: "Menos de um dia depois da vitória do movimento armado, o salazarismo começou a desparecer da vida portuguesa. A obra de reconstrução, segundo disse Spínola, começa com a destruição do que já 'não nos serve mais'" (Junta dissolve polícia e Partido salazaristas, 1974, p. 8).

Um dos episódios com maior destaque é a questão dos presos políticos na prisão de Caxias, em Lisboa. Por um lado, nas palavras da Junta, a liberação de "todos os presos políticos não comprometidos com outros tipos de crimes" (Spínola solta presos políticos, 1974, p. 8), incluindo os militares presos no Levante das Caldas; por outro, a detenção, neste mesmo centro, dos agentes da polícia política que resistiram na sede da DGS (Departamento Geral de Segurança, a antiga PIDE). Segundo o Jornal do Brasil, uma multidão de duas mil pessoas esperava pela libertação dos presos políticos. O título da matéria destinada a esse tópico centraliza, mais uma vez, as ações revolucionárias na figura do general: "Spínola solta presos políticos".

De acordo com o jornal, Lisboa começou a manhã de 26 de abril "aparentando calma total": comércio e bancos abertos. Porém, alguns sinais do cotidiano sinalizavam as 
mudanças em andamento: "indícios do movimento militar, apenas tanques estacionados em pontos estratégicos, papel picado ainda nas ruas e, sinal mais evidente, os jornais 'sem censura', a noticiar tudo e comentar tudo" (Spínola solta presos políticos, 1974, p. 8).

Algumas ocorrências violentas indicavam a perseguição e ataque a agentes da polícia, especialmente na frente da sede da DGS, onde grupos esperavam saída dos policiais que haviam resistido dentro do prédio, "com intenções evidentes de linchar" (Spínola solta presos políticos, 1974, p. 8). Há diversos relatos, na imprensa analisada, de perseguição aos "pides". A liberdade política recém-conquistada explode nas ruas. Já no dia 26 de abril, de acordo com o Jornal do Brasil, milhares de pessoas participaram de um comício na Praça do Rossio, "o primeiro em quase 50 anos, convocado pela Comissão Democrática Eleitoral, uma organização que reúne os Partidos que se opunham ao regime salazarista" (Primeiro comício tem bandeiras, 1974, p. 8).

A 27 de abril, O Estado de S. Paulo destaca em manchete de capa "Spínola liberta presos políticos". Assim como no Jornal do Brasil, os destaques de capa são as primeiras medidas da Junta de Salvação Nacional em seu "programa de pacificação nacional, progresso e justiça" (Spínola liberta presos políticos, 1974, p. 1), a supressão das ultrapassadas estruturas do salazarismo e a "cautela" de Spínola em relação ao "problema do ultramar" (Um novo país, 1974, p. 1). O Estado de S. Paulo destaca em capa as repercussões internacionais, opondo a "cautela" nos EUA e o "elogio" em Moscou (Cautela nos EUA e elogio em Moscou, 1974, p. 1). Da África, as notícias são as mesmas do Jornal do Brasil: apreensão na África do Sul e Rodésia, contentamento pelo fim da ditadura, mas garantia da continuação da luta dos movimentos de independência em Guiné, Angola e Moçambique.

O Estado de S. Paulo manifesta seu posicionamento editorial na página três, focando na falta de experiência e estrutura democrática em Portugal após 48 anos de ditadura. Pelo ponto de vista da política externa brasileira, o entendimento é que as mudanças inevitáveis nas relações entre Portugal e territórios africanos trazem certo alívio e ampliam a possibilidade de diálogo entre as nações, já que os sinais de desajuste entre Brasil e Portugal nesse tema era crescente, sendo "possível supor o próprio rompimento" (Portugal e a diplomacia, 1974, p. 1).

Nas páginas internas, os tópicos sintetizados na capa são aprofundados, com ênfase na reconquista das liberdades democráticas, na reação popular ("O clima é de festa em Lisboa") e nas repercussões na África e na Europa. Os textos noticiosos e citações de jornais e fontes, especialmente dos EUA, Europa e África são muitas vezes idênticos ao Jornal do Brasil, indicando o uso das fontes de agências noticiosas. A diferença nas coberturas manifesta-se nos textos dos correspondentes. Santana Mota, de Lisboa, destaca os primeiros passos da Junta de Salvação Nacional e descreve pormenores do episódio da passagem do poder das mãos de Marcelo Caetano para o general Spínola que indicam que este último não era chefe do MFA até ser chamado a negociar a passagem do poder com o Primeiro-Ministro: "como, no momento, o general não exercia qualquer função de comando no golpe, resolveu-se consultar a direção do movimento, que prontamente concordou em entregar a chefia a Spínola" (Mota, 1974, p. 7). 
O episódio também ocupa uma coluna na página 6 do espaço noticioso, sob o título "O último gesto de Caetano" (O último gesto de Caetano, 1974, p. 6). O texto adiciona alguns detalhes ao relato do correspondente Santana Mota, entre eles, a afirmação de Caetano de que desejava transmitir-lhe o poder "para que este não caísse nas mãos da gentalha" e que a transmissão teria sido realizada "com exemplar dignidade" (O último gesto de Caetano, 1974, p. 6).

De Londres, o correspondente Hermano Alves analisa a conjuntura sob o ponto de vista da Organização do Tratado do Atlântico Norte: "a NATO sairá favorecida". Nessa leitura, a ditadura em Portugal era vista como um empecilho para esse grupo: "um regime democrático em Portugal abre o caminho para que o país participe - como membro - da Comunidade Econômica Europeia. E pode ter grande influência no futuro político da Espanha e também da Grécia" (Alves, 1974, p. 7). Confirma-se ainda, que, na África, as propostas da Junta são consideradas, à esquerda (movimentos de independência africanos) e à direita (comunidade portuguesa nesses territórios), "muito liberais" (Alves, 1974, p. 7).

Gilles Lapouge, de Paris, afirma que “Na França, há simpatia geral”, opinião embasada nas repercussões da imprensa neste país, à esquerda e à direita:

Do ultraconservador L'Aurore ao comunista L'Humanité, os jornais franceses dedicaram ontem páginas inteiras aos acontecimentos portugueses. Mesmo L'Aurore, que em algumas ocasiões apoiou atitudes de Salazar e de Caetano, admitiu, num artigo de Roland Faure, que o golpe foi justificado. L'Humanité, por sua vez, publicou um raro elogio a um golpe militar. (Lapouge, 1974, p. 7)

Lapouge conseguiu uma entrevista com Mário Soares em Paris, que afirmou que "para a oposição portuguesa, há apenas uma solução: pôr fim à guerra e reconhecer a personalidade das colônias" (Lapouge, 1974, p. 7). Note-se que Soares não fala em independência total. A posição de cautela da Junta em relação às questões africanas é corroborada pela leitura da imprensa, somada à análise do passado de Spínola, voluntário na Guerra Civil Espanhola ao lado de Franco e, até pouco tempo atrás, colaborador do regime salazarista:

Algumas horas depois da entrevista, havia sinais, em Lisboa, de que o novo governo não pretende iniciar os contatos com os líderes guerrilheiros. Pelo menos é a opinião do jornalista Antonio Diez, da revista L'Express, que declarou ao Estado: "Creio que Spínola não irá tão longe na liberalização como se creditava. Na minha opinião, a vida democrática será revitalizada, mas dentro de um regime autoritário". (Lapouge, 1974, p. 7)

Finalmente, a 28 de abril, está a notícia de que o Brasil foi o primeiro país a reconhecer o novo regime de Portugal, simplesmente através da troca de comunicados entre os dois países. Em O Estado de S. Paulo, a manchete principal é: "Brasil reconhece junta portuguesa". Na capa estão, ainda, novas informações sobre as manifestações populares 
("Após quase 50 anos, um dia de euforia em Lisboa") e as preocupações iniciais de Spínola ("Spínola teme o uso indevido da liberdade"). A capa é composta com uma foto com a legenda "estudantes desmantelam carro de um agente da antiga polícia-secreta". Das ruas de Lisboa, os correspondentes Clóvis Rossi e Ewaldo Dantas reportam os comícios e manifestações políticas, especialmente de grupos de esquerda e as expressões de ódio à PIDE, que levaram a alguns atos violentos, como o desmantelamento do automóvel e a perseguição a um policial identificado e acossado pela multidão dentro de um banco, de onde foi retirado e levado preso pelos soldados. Prédios e ônibus amanheceram marcados em tinta spray encarnada, com o slogan: "O primeiro de maio é vermelho". Outros slogans eram: "Guerra do povo à guerra colonial", "Pão, paz, liberdade, democracia e independência nacional". Os militantes mais jovens já pediam "Abaixo Spínola". Os jornalistas recolheram, ainda, o depoimento de presos políticos recém-libertados, os quais relataram as torturas nas prisões portuguesas, incluindo privação do sono, do contato com a família e espancamentos. Os jornalistas insistiam em perguntar aos presos se a polícia lhes havia "tirado sangue", o que os entrevistados negaram.

Ainda na capa do O Estado de S. Paulo de 28 de abril, estão as manifestações de Spínola, que, frente à euforia popular, declara: "é natural que o povo dê vazão à sua alegria. Mas não devemos nos esquecer que se trata de um povo que há meio século não tem consciência do uso das liberdades". A ideia de que a privação da ditadura desabilitou o povo para o exercício da liberdade e da política, de vertente autoritária, é recorrente, tanto entre as autoridades quanto na opinião de jornais como O Estado de S. Paulo, como já vimos.

É apenas nas notícias publicadas nesse dia 28 de abril que O Estado de S. Paulo atenta para a constituição básica do MFA: um movimento da oficialidade jovem. Hamilton de Souza, enviado especial de O Estado de S. Paulo a Lisboa, escreve:

mas, nos meios jornalísticos comenta-se que a maioria das medidas anunciadas pela Junta de Salvação Nacional - com exceção da questão das províncias - não reflete o pensamento de Spínola. As mesmas fontes dizem que tais medidas foram impostas pela oficialidade jovem das Forças Armadas. (Souza, 1974, p. 7)

O correspondente descreve, ainda, a adesão popular ao inusitado golpe de Estado, corroborando a visão de que o 25 de Abril contrariou todas as expectativas em relação a um movimento desse tipo:

Lisboa não parece ter sido palco de um golpe de Estado. A não ser nas proximidades dos quartéis e postos-chave ocupados pelas tropas do general António de Spínola, não há nenhuma movimentação militar ou indícios de repressão policial. (...) A adesão ao novo governo é quase total, e a cada momento são transmitidos, pelas emissoras de rádio, já em programação normal - os comunicados de apoio procedentes de diversos setores de atividades. Os jornais, livres da censura, dedicam quase todo o espaço aos 
recentes acontecimentos, realçando sempre a libertação dos presos políticos, a normalização da vida política e as manifestações de apoio à junta. A incrível rapidez com que o povo aderiu ao movimento das Forças Armadas leva a crer que a ansiedade pela mudança do regime, mantido durante 48 anos, estava decididamente arraigada na mente de todos os cidadãos portugueses. (Souza, 1974, p. 7)

O editorial de 28 de abril de O Estado de S. Paulo reflete sobre os acontecimentos em Portugal, revelando, mais uma vez, o conservadorismo e anticomunismo do diário paulistano. Ao comentar a euforia sobre as perspectivas de redemocratização em Portugal, afirma que, de forma "realista", a democracia tem "condicionantes morfológicas" e que é conquistada pelo "amadurecimento". Sendo assim, para O Estado de S. Paulo, o povo português não estaria preparado para a democracia, já que a educação popular para essa forma de governo não era "prioridade do programa do governo salazarista" e que "outros totalitários, desta vez da esquerda sob influência exógena" poderiam beneficiar-se do caos e da desordem.

Ora, há quase cinquenta anos, Salazar estabeleceu sua ditadura para remediar o caos e a desordem em que a desintegração política precipitara o país. Esse quase meio século de ditadura, por sua vez, afastou totalmente o povo das práticas democráticas, já que a educação popular para a democracia não foi uma das prioridades do programa do governo salazarista, preocupado principalmente com a necessidade de reorganizar, consolidar e disciplinar a administração pública e assegurar bases financeiras para a produção. Assim sendo, não há como negar que a democratização deve ser progressiva (...) para que o povo português, não preparado e amadurecido para assumir as responsabilidades culturais e morais do autogoverno, vendo-se surpreendido pela obtenção dos direitos advindos da liberdade, esqueça-se dos deveres a ela inerentes e passe a interpretá-la e a exercê-la no sentido da libertinagem. A libertinagem, todos o sabemos, leva ao caos e à desordem, dos quais irão beneficiar-se outros totalitários, desta vez da esquerda sob influência exógena. (Os caminhos dos militares portugueses, 1974, p. 3)

A 28 de abril, a manchete do Jornal do Brasil é bastante similar à de $O$ Estado de $S$. Paulo, trocando, apenas, "junta portuguesa" por "novo governo de Portugal": "Brasil reconhece novo governo de Portugal". Assim como o diário paulistano, a ênfase é no fato de o Brasil ser o primeiro país a realizar esse reconhecimento e nas promessas de Spínola de autodeterminação e independência progressivas nos territórios na África. $\mathrm{O}$ jornal transcreve a troca de mensagens entre a Junta e o Ministério das Relações Exteriores. Diferente de $O$ Estado de S. Paulo, dá ênfase a elementos que seriam perpetuados como símbolos do imaginário desse acontecimento: a senha para o golpe foi a música, proibida pela censura, Grândola, Vila Morena, de José Afonso. Jornal do Brasil reproduz 
a letra da canção em box. Sobre os cravos vermelhos, o enviado especial do Jornal do Brasil, José Silveira, afirma: "soldados do Exército e Fuzileiros Navais, em uniformes de campanha, portam fuzis automáticos leves. Muitos deles trazem cravos vermelhos nos canos das armas, oferecidos pela população" (Silveira, 1974, p. 3).

Ao tratar da questão africana, Jornal do Brasil dá destaque aos rumores de que colonos portugueses em Moçambique "estariam preparando um plano para libertar o ex-presidente Marcelo Caetano de seu atual confinamento na Ilha da Madeira e confiar-lhe o Governo de Moçambique, que se declararia independente de Portugal". O plano é considerado "totalmente inexequível" pela Junta, tanto pela prisão de Caetano quanto pela adesão dos militares portugueses em Moçambique à Revolução (Colonos de Moçambique querem libertar Caetano, 1974, p. 19).

A narrativa sobre a Revolução de 25 de Abril termina, em nosso recorte, de forma aberta. Para onde o golpe de Estado efetuado pelos militares em Portugal conduziria este país? As forças armadas entregariam o poder aos civis? A democracia conseguiria se estabelecer? No Brasil, 10 anos de ditadura militar cerceavam a vida política e as liberdades individuais. Os ventos do além-mar poderiam ser um bom presságio. A charge de Ziraldo (Figura 3), publicada no Jornal do Brasil, sintetiza bem essa expectativa, ao invocar a letra do Hino da Independência do Brasil.

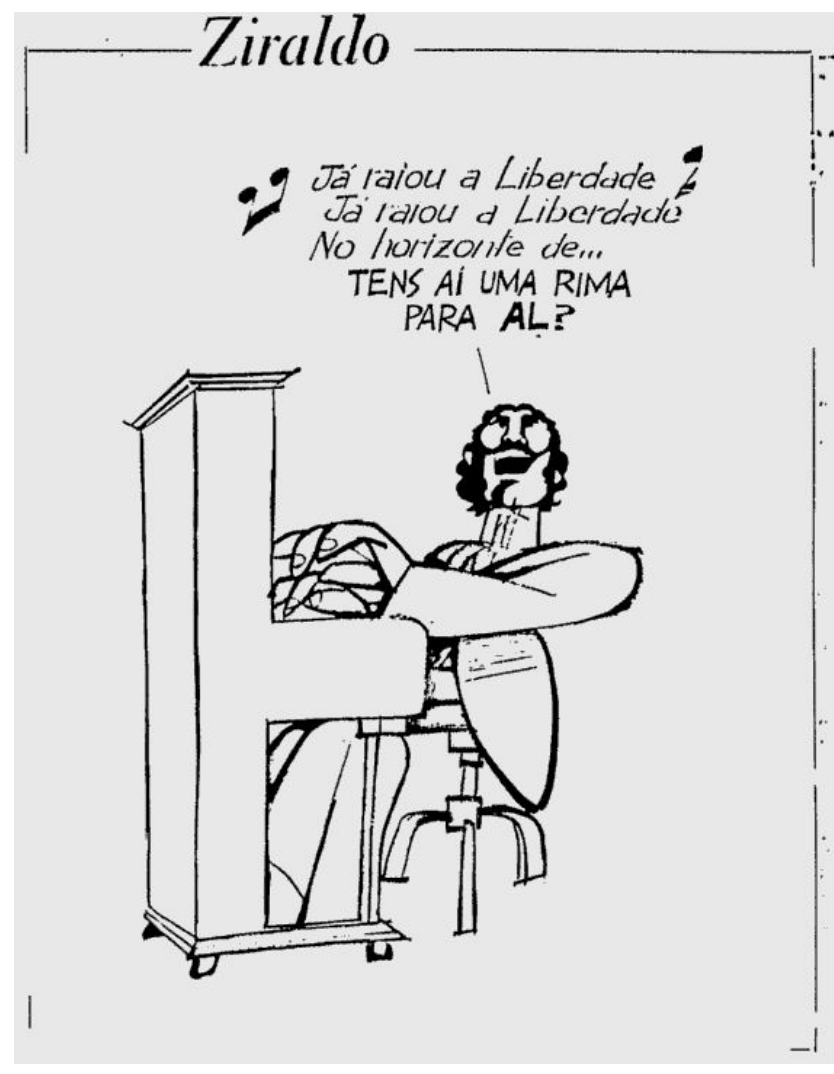

Figura 3: Para Ziraldo, a liberdade raiou em Portugal

Fonte: Jornal do Brasil, 28 de abril de 1974, p. 6 
Um dos pontos mais repercutidos pela imprensa brasileira, com certa nostalgia, é o da liberdade de expressão. Com a euforia popular e a súbita liberdade de expressão, Spínola afirma que o objetivo é "criar uma imprensa mais responsável: 'Todos os jornais devem transformar-se em instrumentos válidos. Não podemos permitir que se crie um clima de irresponsabilidade"” (Spínola teme o uso indevido da liberdade, 1974, p. 1). O mesmo temor em relação ao "uso indevido da liberdade" é direcionado às colônias, caso no qual Spínola vê que há confusão entre autodeterminação (postura que defende) e independência, e também ao cotidiano dos cidadãos portugueses, há tanto tempo privados da liberdade. A Charge de Ziraldo, publicada no Jornal do Brasil, volta-se também ao tema da liberdade e sugere que o povo português anda "esquecido" (Figura 4).

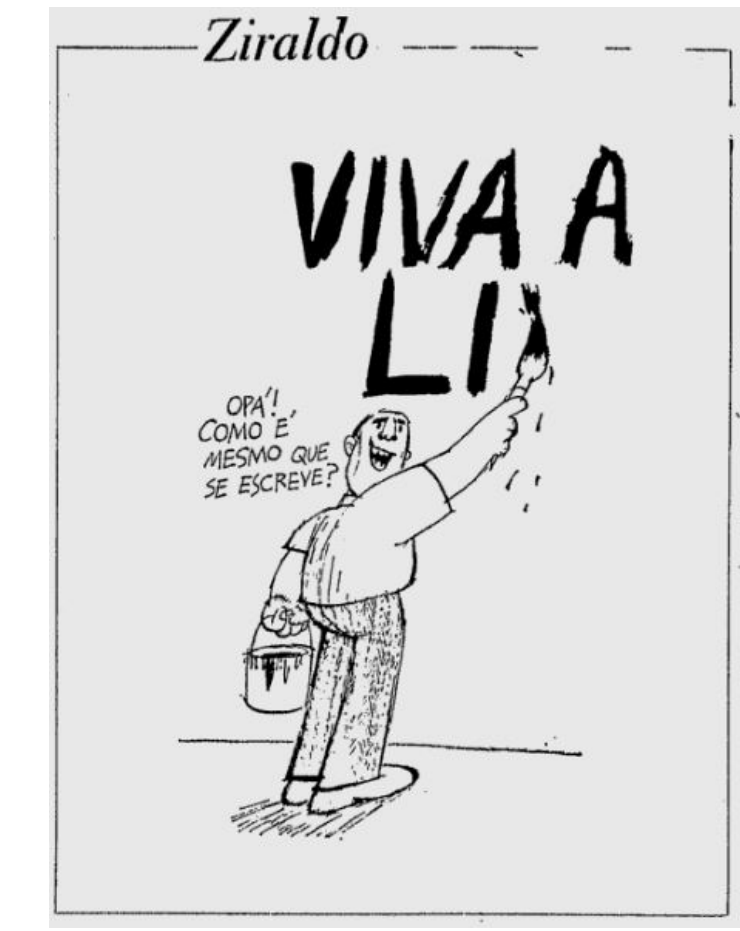

Figura 4: Estariam os portugueses desacostumados com a liberdade? Fonte: Jornal do Brasil, 27 de abril de 1974, p. 6

\section{NOTAS CONCLUSIVAS}

Vimos, nesta recomposição da narrativa da imprensa brasileira sobre o 25 de Abril, que a tentativa de reescrever a liberdade enfrentou muitos desafios. Em termos de protagonismo, percebemos que a horizontalidade do movimento dos jovens oficiais provocou confusão, e as manchetes acabaram por focar na figura (já conhecida) de Spínola. A Revolução foi vista como previsível, porém, seu caráter inusitado (popular e pacífico) provocaram surpresa. $O$ tema da liberdade repercute na política interna: mesmo sob censura prévia (O Estado de S. Paulo costumava publicar sonetos de Camões nos espaços cortados pela censura), vimos a defesa de um ponto de vista autoritário no espaço opinativo desse jornal: o povo português estaria despreparado para a vida democrática. 
A cobertura noticiosa, um tanto pasteurizada pelos textos das agências, ganha cores nos relatos dos colunistas e correspondentes. As relações internacionais entremearam-se na cobertura, demonstrando que a ditadura portuguesa agradava a poucos, e que se projetava, no Brasil, um novo arranjo de forças na comunidade lusófona. Muito pouco se noticiou sobre as repercussões nos territórios africanos, lacuna que, sinalizamos, muito contribuiria para uma compreensão mais abrangente dos significados do 25 de Abril.

\section{REFERÊNCIAS}

A queda do regime português (1974, 26 de abril). O Estado de S. Paulo, p. 3.

Alves, H. (1974, 26 de abril). Na Inglaterra, simpatias são mal disfarçadas. O Estado de S. Paulo, p. 9.

Alves, H. (1974, 27 de abril). A NATO sairá favorecida. O Estado de S. Paulo, p. 7.

Brasil aguarda em silêncio (1974, 26 de abril). Jornal do Brasil, p. 4.

Brasil-Portugal (1974, 26 de abril). Jornal do Brasil, p. 6.

Castello Branco, C. (1974, 26 de abril). A libertação de Portugal. Jornal do Brasil, p. 4.

Cautela nos EUA e elogio em Moscou (1974, 27 de abril). O Estado de S. Paulo, p. 1.

Chagas, C. (1974, 26 de abril). Fim do regime apenas traduz a vontade popular. O Estado de S. Paulo, p. 9.

Colonos de Moçambique querem libertar Caetano (1974, 28 de abril). Jornal do Brasil, p. 19.

Como foi o movimento rebelde (1974, 26 de abril). Jornal do Brasil, p. 2.

Fico, C. (2012). Além do golpe: versões e controvérsias sobre 1964 e a Ditadura Militar. Rio de Janeiro: Record.

Frelimo rejeita a proposta (1974, 28 de março). O Estado de S. Paulo, p. 2.

Geisel faz apelo pela unidade (1974, 16 de março). O Estado de S. Paulo, p. 1.

Informe Jornal do Brasil (1974, 26 de abril). Jornal do Brasil, p. 10.

Itamaraty não foi surpreendido (1974, 26 de abril). O Estado de S. Paulo, p. 1.

Junta dissolve polícia e Partido salazaristas (1974, 27 de abril). Jornal do Brasil, p. 8.

Lacerda, C. (1974, 9 de abril). Portugal acha a solução. O Estado de S. Paulo, p. 5.

Lapouge, G. (1974, 26 de abril). Por momentos, a França esquece a campanha eleitoral. O Estado de S. Paulo, p. 9.

Lapouge, G. (1974, 28 de abril). Na França, há simpatia geral. O Estado de S. Paulo, p. 7.

Lisboa sufoca revolta mas crise se agrava (1974, 17 de março). O Estado de S. Paulo, p. 1.

Livro se esgota em duas cidades (1974, 27 de abril). Jornal do Brasil, p. 9.

Mário Soares oferece apoio (1974, 26 de abril). O Estado de S. Paulo, p. 9. 
Martinho, F. C. P. (2007). Léguas a nos separar: o que levou o regime militar brasileiro a apoiar um movimento de esquerda como a Revolução dos Cravos em Portugal? Revista de História da Biblioteca Nacional, 42, 63-68.

Martins, M. L. (1992). A dona de casa e a caravela transtlântica. Estudo sócio-antropológico sobre o imaginário salazarista. Cadernos do Noroeste, 5, 191-204. Retirado de http://repositorium.sdum.uminho. $\mathrm{pt} / \mathrm{handle} / 1822 / 25357$

Martins, M. L. (2014). Os mitos de origem no salazarismo - o passado como se fora presente. In M. M. Baptista, J. E. Franco \& B. Cieszynska (Eds.), Europa das nacionalidades: imaginários, identidades e metamorfoses políticas (pp. 185-191). Coimbra: Grácio Editor.

Martins, M. L. (2017). O olho de Deus no discurso salazarista. Porto: Afrontamento.

Militares acabam salazarismo e prometem eleição (1974, 26 de abril). Jornal do Brasil, p. 2.

Mota, S. (1974, 16 de março). Em Portugal, a situação agora é menos confusa. O Estado de S. Paulo, p. 2.

Mota, S. (1974, 26 de abril). Às 4 da tarde, o final de uma era. O Estado de S. Paulo, p. 1.

Mota, S. (1974, 27 de abril). Junta inicia sua missão. O Estado de S. Paulo, p. 7.

Motta, L. G. (2005). A análise pragmática da narrativa jornalística. In Anais do XXVIII Congresso Brasileiro de Ciências da Comunicação (pp. 1-15). Rio de Janeiro: UERJ. Retirado de http://www.portcom.intercom.org. $\mathrm{br} / \mathrm{pdfs} / 105768052842738740828590501726523142462 . p d f$

Mundo aguarda o desfecho da crise (1974, 26 de abril). O Estado de S. Paulo, p. 9.

Nora, P. (1979). O retorno do fato. In J. Le Goff, \& P. Nora, História: novos problemas (pp. 179-193). Rio de Janeiro: Francisco Alves.

Nora, P. (1983). Monster events. Discourse, 5, 5-20.

O último gesto de Caetano (1974, 27 de abril). O Estado de S. Paulo, p. 6.

Os caminhos dos militares portugueses (1974, 28 de abril). O Estado de S. Paulo, p. 3.

Os feitos de Spínola o destacam como líder (1974, 17 de março). O Estado de S. Paulo, p. 14.

Para Lacerda, era previsível o que aconteceu (1974, 26 de abril). O Estado de S. Paulo, p. 9.

Patrício rejeita alteração (1974, 17 de março). O Estado de S. Paulo, p. 1.

Portugal à margem do mundo (1974, 26 de abril). Jornal do Brasil, p. 4.

Portugal e a diplomacia (1974, 27 de abril). O Estado de S. Paulo, p. 1.

Primeiro comício tem bandeiras (1974, 26 de abril). Jornal do Brasil, p. 8.

Rebeldes tentam evitar choque armado em Lisboa (1974, 25 de abril). Jornal do Brasil, p. 14 [ $3^{\circ}$ clichê].

Recrudesce em Portugal a crise político-militar (1974, 16 de março). O Estado de S. Paulo, p.1.

Rosas, F. (2013). Salazar e o poder - a arte de saber durar. Lisboa: Tinta-da-China.

Silva, J. M. da. (2006). As tecnologias do imaginário. Porto Alegre: Sulina. 
Silveira, J. (1974, 28 de abril). Novos hóspedes nas prisões. Jornal do Brasil, p. 3.

Sodré, M. (2009). A narração do fato: notas para uma teoria do acontecimento. Petrópolis: Vozes.

Souza, H. de (1974, 28 de abril). Oficialidade jovem parece controlar a Junta. O Estado de S. Paulo, p. 7.

Spínola liberta presos políticos (1974, 27 de abril). O Estado de S. Paulo, p. 1.

Spínola solta presos políticos (1974, 27 de abril). Jornal do Brasil, p. 8.

Spínola teme o uso indevido da liberdade (1974, 28 de abril). O Estado de S. Paulo, p. 19.

Tropa rebelada marcha em direção à Lisboa (1974, 25 de abril). Jornal do Brasil, p. 14 [2 clichê].

Um novo país (1974, 27 de abril). O Estado de S. Paulo, p. 1.

Vieira, J. \& Monico, R. (2014). Nas bocas do mundo: o 25 de Abril e o PREC na imprensa internacional. Lisboa: Tinta-da-China.

\section{NotA BIOGRÁFICA}

Camila Garcia Kieling é Professora Adjunta na Escola de Comunicação, Artes e Design - Famecos da Pontifícia Universidade Católica do Rio Grande do Sul. Doutora em Comunicação Social pela mesma instituição.

Email: camila.kieling@gmail.com

Morada: Avenida Otto Niemeyer, 1025 apto. 707B - 91910-001 - Porto Alegre, RS, Brasil

* Submetido: 15.05.2018

* Aceite: 21.06.2018 